\title{
Impact of Middle Term Points in Total Score in the Context of Face to Face and Online Teaching
}

\author{
Nazmi Xhomara \\ Assoc. Prof. Dr Lecturer, Department of Mathematics and \\ Statistics, Faculty of Information Technology and Innovation, \\ Luarasi University, Tirana Albania \\ Majlinda Hala \\ Dr Lecturer, Department of Picture, Faculty of Arts, \\ University of Arts, Tirana, Albania
}

\section{Abstract}

The study aimed to investigate the differences between face-to-face and online teaching, as well as the effect of middle term points in total score in the context of face-to-face and online teaching. Correlational research design and a database of students' attendance and results to get secondary data were used in the study. A random cluster sample of students from the bachelor's degree program was taken. The study demonstrated that there is a mean difference in the population or, equivalently, that the two-sample means were drawn from different populations of online vs face-to-face teaching. The study showed a high positive correlation between middle term points and total score variables, $r=.846$ for the experimental group and $r=.731$ for the control group, where increases in middle term points were associated with increases in total score values. It can also be concluded that the total variance of total score levels explained by middle term points (the model) is $53.4 \%$, the other variance may be explained by other variables; meanwhile, Beta Standardized coefficient of middle term points explains $84.6 \%$ of the variance in the total score of their academic performance for the experimental group and $73.1 \%$ for the control group. This indicates that middle term points influence strongly the total score of students' academic performance.

Keywords: face-to-face teaching, online teaching, middle term points, the total score

\section{Introduction}

The COVID-19 pandemic has created the largest disruption of education systems in human history, affecting nearly 1.6 billion learners in more than 200 countries. Closures of schools, institutions, and other learning spaces have impacted more than $94 \%$ of the world's student population. Educational institutions are currently based 
only on face-to-face lectures in a classroom. Although many academic units have also started blended learning, still a lot of them are stuck with old procedures. The sudden outbreak of a deadly disease called Covid-19 caused by a Corona Virus (SARS-CoV-2) shook the entire world. Educational institutions have adopted online teaching methods in response to this crisis. Events caused by the COVID-19 pandemic have required educators to move away from face-to-face lessons and adopt online teaching. Educators have utilized a range of online synchronous meeting tools to facilitate student learning. Learning management systems have become a key component of teaching and learning in higher education.

The middle term in the context of face-to-face and online teaching is supposed to be the important variable that influences the total score of students' academic performance. The purpose of the study is to investigate the differences between faceto-face and online teaching, as well as the effect of middle term points in total score in the context of face-to-face and online teaching. The research questions include: (1) is there a difference in the total score means of face-to-face teaching compared to online teaching? (2) is there a variance in the total score explained by middle term points in the context of face-to-face and online teaching?

\section{Literature review and hypothesis development}

\section{Conceptual framework}

The theoretical framework is based on an extensive review of existing evidence about multiple intelligences and learning styles through ERIC, Sage, and EBSCO, using the keywords middle term, total score, as well as face-to-face teaching and online teaching. Figure1 summarizes the results from the review and proposes a set of relationships among two main constructs: middle term, and total score of students' performance.

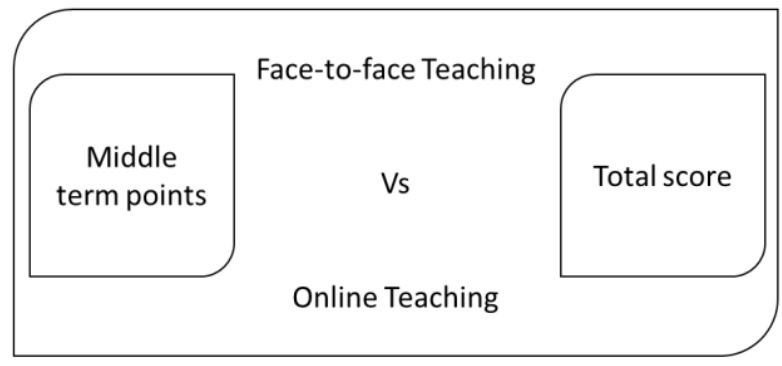

Figure: Conceptual framework

\section{Face-to-face teaching vs online teaching}

Face-to-face teaching and online teaching are considered complementary strategies, especially in the COVID 19 time. The COVID-19 pandemic has provided teachers with an opportunity to pave the way for introducing digital learning (Pokhrel, \& Chhetri, 2021), and an effective tutoring system is an effective tool and significantly improves learning outcomes (Wang, \& Lin, 2017). Teachers' ages, and the annotation tools, 
polls, breakout rooms, and video and screen sharing of various online teaching platforms, can determine which one is used by different individuals (Zhao et al., 2020; Kohnke, \& Moorhouse, 2020); meanwhile, Heble (2007) indicate that while online teaching did not have a significant effect on the student's final exam results, it certainly has allowed them to engage in an active and uninhibited exchange of opinions and ideas. The length and depth of engagement as well as the interactions during the delivery of the online course differ from face-to-face teaching (Conceição, 2006; Cheung, 2021); and Senior (2010) identifies five dimensions of connectivity, ranging from the connections that effective teachers make with their students in conventional classroom situations to the ways that effective teachers intuitively seek to meld their students into learning communities in blended and distance learning environments.

Face-to-face learning is perceived as superior to online learning and the existence of skill and capacity barriers that hinder improved online teaching and learning practice, even where professional development opportunities exist for lecturers (Kite, Schlub, Zhang, \& Choi, 2020; Moorhouse, \& Walsh, 2021); meanwhile, Dhawan (2020) indicate the growth of EdTech Start-ups during the time of pandemic and includes suggestions for academic institutions of how to deal with challenges associated with online learning. Arco-Tirado, Fernández-Martín, \& Hervás-Torres (2020) found out the impact of a peer-tutoring program on academic performance among first-year students; meanwhile, Lessard, and Juvonen (2019) revealed that cross-class friendship decrease class-based achievement differences during a developmental phase when friends are particularly important. Bayrakdaroglu and Hekim (2020) showed a positive relationship between the stress levels towards academic expectations and goal commitment of pre-service teachers, and Scales, Van Boekel, Pekel, Syvertsen, \& Roehlkepartain (2020) found that developmental relationships strongly predicted academic motivation at both the beginning and end of the school year.

Elder (2021), as well as Anderton (2017), showed that high school performance, institutional fit, and the Tertiary Admissions Rank as significant predictors of academic performance; meanwhile, Smith, Giugliano, \& DeOrio, 2018) observed a positive relationship between partnering in an introductory course and higher project scores in a future course. Thus, it is evidenced that, the investigation of the relationship between face-to-face teaching and online teaching, as resulted in previous research, is important. Therefore, based on previous research it is hypothesized that:

$\mathrm{H} \#$ 1: The total score means in face-to-face teaching is higher than the total score means in online teaching.

H0: $\mu$ face to face teaching $=\mu$ online teaching

H1: $\mu$ face to face teaching $\neq \mu$ online teaching 


\section{Relationships between middle term points and total score}

The middle term points is assumed to be one of the important variables that impact the total score of students' academic performance at the university. Guinocor, Almerino, Mamites, Lumayag, Villaganas, \& Capuyan (2020) found out that there is a significant positive high correlation between the study orientations of the students considering their academic performance in terms of their Graded Point Average (GPA), and Rudd, and Honkiss (2020) revealed that higher language proficiency levels were associated with higher standards of GPA across all measures. Studying previously, attending class, studying all the topics for the exams, and first-term GPA was associated positively with the grade point average obtained (Renes et al., 2020; Nadasen, \& List, 2016); meanwhile, Butler (2020) revealed that middle-level academics are described as being at a mid-point in their careers and universally appear to represent a substantial percentage of academic personnel in tertiary institutions. There is a positive relationship between high school grades, prior performance, academic engagement, psychological capital, and academic performance (Danilowicz-Gösele, Lerche, Meya, \& Schwager, 2017; Kleemola, \& Hyytinen, 2019; Martínez, Youssef-Morgan, Chambel, \& Marques-Pinto, 2019); meanwhile, Craft (2019) demonstrates that students of low socioeconomic status, and those of lower entry ranks, were successful in their first year. Locus of control, tutoring, gender and academic self-efficacy measure identified as self-assurance had positive and significant effects on academic performance (Drago, Rheinheimer, \& Detweiler, 2018; Balkis, \& Duru, 2017); meanwhile, Ferrão, \& Almeida (2019) suggests that $34 \%$ of the variability in grade point average is due to differences among courses and that $80 \%$ of such variability is explained by the field of study.

Abdullah, \& Mirza (2019) observed significant correlations in previous cumulative examination scores and entry qualification scores; meanwhile, Stone, Shaner, \& Fendrick (2018) found out that interventional strategies targeting academically underprepared students increase their success by providing a preparatory course before the main course. There is a significant relationship between several of the career guidance variables with grade point average (Carson, \& Reed, 2015; Iscan, \& Balyer, 2019), and high school study results, preparative activities, expectations, capabilities, motivation, and attitude predict students' academic performance (Meijer et al., 2019; Wanzer, Postlewaite, \& Zargarpour, 2019). Hence, there is evidence that the investigation of the relationship between middle term points and total score, as resulted by previous research, indicates the scientific and practical importance. Therefore, based on previous research it is hypothesized that:

$\mathrm{H} \#$ 2: The variance in the total score is explained by middle term points in the context of face to face and online teaching 


\section{Methodology}

\section{Method}

A quantitative approach was the method used in the research. The correlational research design was used. The first-year master's students of a large university were selected to be used in the study.

\section{Sample and data collection}

A database of students' attendance and results to get secondary data were used in the study. A random cluster sample of the experimental group of students $(\mathrm{N}=130)$ and a random cluster sample of the control group of students were used in the study. A breakdown of the experimental group of students included 74 females (57 percent) and 56 males (43 percent); meanwhile, the control group of students included 61 females ( 55 percent), and 50 males ( 45 percent). The random cluster sample of the experimental group of students was selected in the law faculty of the university; meanwhile, the random cluster sample of the control group of students was selected in the economics and information technology and innovation faculty of the university.

\section{Analysis}

An independent-samples t-test was conducted comparing the mean of online teaching students vs face-to-face teaching students of those having passed or failed the course. Levene's test for equality of variances was conducted to test the null hypothesis that the variances in each population (from which the samples were drawn) are equal. Pearson product-moment correlation coefficient was used to assess the relationship between middle term points and total score of academic performance. Linear multivariate regression was used to assess the ability of one control measure to predict the total score of academic performance by middle term points. Preliminary analyses were conducted to ensure no violation of the assumptions of normality, linearity, multicollinearity, and homoscedasticity.

\section{Results and discussion}

\section{Descriptive statistics}

Table 1: Frequencies of online teaching vs face to face teaching variable Online Teaching Attendance Face to face teaching attendance

\begin{tabular}{llllll}
\hline \hline & & Frequency & Percent & Frequency & Percent \\
\hline Valid & Low level & 23 & 17.7 & 15 & 13.5 \\
& Medium & 49 & 37.7 & 49 & 44.1 \\
& level & & & & \\
& High level & 58 & 44.6 & 47 & 42.3 \\
Total & 130 & 100.0 & 111 & 100.0 \\
\hline \hline
\end{tabular}


As shown in Table 1, 17.7\% of the experimental group and 13.5\% of the control group is evidenced to have a low level of online teaching vs face to face teaching; $37.7 \%$ of the experimental group and $44.1 \%$ of control group medium level; and $44.6 \%$ of the experimental group and $42.3 \%$ of control group a high level of online teaching vs face to face teaching. Therefore, there are few differences between online teaching and face-to-face teaching attendance.

Table 2: Frequencies of middle term points variable

Middle Term points

Experimental group

Control group

\begin{tabular}{llllll}
\hline \hline & & Frequency & Percent & Frequency & Percent \\
\hline Valid & Low level & 23 & 17.7 & 45 & 40.5 \\
& Medium & 46 & 35.4 & 18 & 16.2 \\
& level & & & & \\
& High level & 61 & 46.9 & 47 & 42.3 \\
Total & 130 & 100.0 & 111 & 100.0 \\
\hline \hline
\end{tabular}

As shown in Table 2, 17.7\% of the experimental group and $40.5 \%$ of the control group is evidenced to have a low level of middle term points; $35.4 \%$ of the experimental group and $16.2 \%$ of control group medium level; and $46.9 \%$ of the experimental group and $42.3 \%$ of control group a high level of middle term points. Therefore, there are differences between and face-to-face teaching and online teaching middle term points, especially in the low and medium levels.

Table 3: Frequencies of total score variable

Total Score

\begin{tabular}{|c|c|c|c|c|c|}
\hline \multicolumn{3}{|c|}{ Experimental group } & \multicolumn{3}{|c|}{ Control group } \\
\hline & & Frequenc & & & \\
\hline & & $y$ & Percent & Frequency & Percent \\
\hline \multirow[t]{8}{*}{ Valid } & Failed level & 25 & 19.2 & 36 & 32.4 \\
\hline & Very low level & 12 & 9.2 & 21 & 18.9 \\
\hline & Low level & 15 & 11.5 & 5 & 4.5 \\
\hline & $\begin{array}{l}\text { Lower medium } \\
\text { level }\end{array}$ & 40 & 30.8 & 4 & 3.6 \\
\hline & $\begin{array}{l}\text { Upper medium } \\
\text { level }\end{array}$ & 25 & 19.2 & 7 & 6.3 \\
\hline & High level & 12 & 9.2 & 17 & 15.3 \\
\hline & Very high level & 1 & .8 & 21 & 18.9 \\
\hline & Total & 130 & 100.0 & 111 & 100.0 \\
\hline
\end{tabular}


As shown in Table 3, 19.2\% of the experimental group and 32.4\% of the control group is evidenced to have failed; $20.7 \%$ of the experimental group and $23.4 \%$ of the control group is evidenced to have very low or low level; $50 \%$ of the experimental group and $9.9 \%$ of the control group is evidenced to have lower or upper-medium level, and $17.2 \%$ of the experimental group and $34.2 \%$ of the control group is evidenced to have a high or very high level. Therefore, there are differences between and face-to-face teaching and online teaching total scores, especially in the medium and high levels.

\title{
Inferential statistics: Test of hypothesis
}

\section{H \# 1}

Table 4: The output of the independent-samples t-test

Group Statistics_Experimental group

\begin{tabular}{l|lllll}
\hline & $\begin{array}{l}\text { Total } \\
\text { Score_Recoded }\end{array}$ & $N$ & Mean & $\begin{array}{l}\text { Std. } \\
\text { Deviation }\end{array}$ & $\begin{array}{l}\text { Std. Error } \\
\text { Mean }\end{array}$ \\
\hline $\begin{array}{l}\text { Online Teaching } \\
\text { Attendance }\end{array}$ & Fail & 25 & 1.12 & .332 & .066 \\
\hline \hline & Pass & 105 & 2.54 & .519 & .051 \\
\hline \hline & Group Statistics_Control group & & & & \\
\hline & Total & & & Std. & Std. Error \\
& Score_Recoded & $N$ & Mean & Deviation & Mean \\
\hline $\begin{array}{l}\text { Face to face } \\
\text { teaching } \\
\text { attendance }\end{array}$ & Fail & 36 & 1.5833 & .50000 & .08333 \\
\hline \hline
\end{tabular}

Table 4 shows that for the experimental group, the sample means of students who passed the course (105) is much higher than the sample means of students who failed the course (25); meanwhile, for the control group, the sample mean of students who passed the course (75) is higher than the sample mean of students who failed the course (36).

Table 5: The output of the Levene's Test for Equality of Variances Independent Samples Test_Experimental group

\author{
Levene's \\ Test for \\ Equality \\ of \\ Variances $t$-test for Equality of Means
}




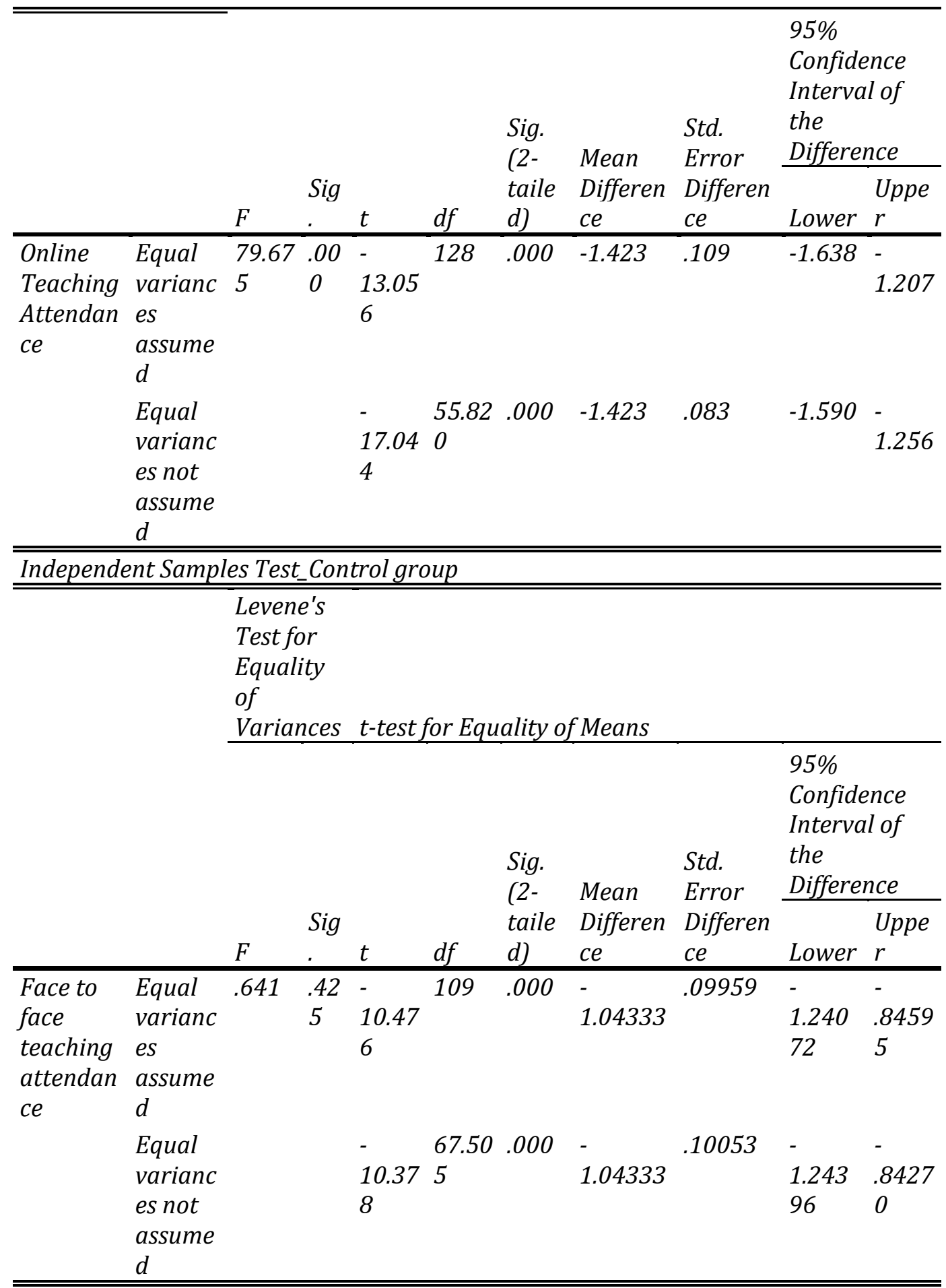


The sample mean for the experimental group of those having passed was equal to 105 , while the sample mean of those failing the course was 25; meanwhile, for the control group, the sample mean of those having passed was equal to 75 , while the sample means of those failing the course was 36 . The difference was found to be statistically significant ( $p=0.000$, equal variances assumed), for the experimental as well as for the control group. Related to the experimental group, a 95\% confidence interval was also computed revealing that we could be 95\% confident that the true mean difference lies between -1.638 and -1.207 . Related to the control group, a $95 \%$ confidence interval was also computed revealing that we could be $95 \%$ confident that the true mean difference lies between -1.24072 and -.85595 .

The obtained $t$ for the experimental group is equal to -13.056, on 128 degrees of freedom, and -10.476, on 109 degrees of freedom for the control group, with an associated p-value of 0.000 in two cases. That is, the probability of obtaining a mean difference (of -1.423 for the experimental group; and -1.04333 for the control group) such as it is observed when sampling from this population is approximately 0.000 (about 1 in 1000). Since such a difference is so unlikely under the null hypothesis of no mean difference, the null hypothesis is rejected and infer the statistical alternative hypothesis that there is a mean difference in the population or, equivalently, that the two-sample means were drawn from different populations.

The result was consistent with previously reported works (Pokhrel, \& Chhetri, 2021; Zhao et al., 2020; Kohnke, \& Moorhouse, 2020; Kite, Schlub, Zhang, \& Choi, 2020; Moorhouse, \& Walsh, 2021; Dhawan, 2020; Bayrakdaroglu, and Hekim, 2020; Scales, Van Boekel, Pekel, Syvertsen, \& Roehlkepartain, 2020; Anderton, 2017), who argued that the total score of students' academic performance in the face to face teaching is different compared to the total score in online teaching.

Therefore, hypothesis \# 1: The total score' means in face-to-face teaching is higher than the total score mean in online teaching, is supported.

\section{H \# 2}

Table 6: Pearson correlation outputs of the relationships between middle term points and total score variables

Correlations

\begin{tabular}{llllll}
\multicolumn{3}{c}{ Experimental group } & $\begin{array}{l}\text { Control } \\
\text { group }\end{array}$ \\
\hline \hline & & Middle & & Middle \\
& & Total & Term & Term \\
Score & points & Total Score & points \\
\hline Pearson & Total Score & 1.000 & .731 & 1.000 & .846 \\
Correlation & Middle Term & .731 & 1.000 & .846 & 1.000 \\
& points & & & & \\
\hline
\end{tabular}




\begin{tabular}{|c|c|c|c|c|c|}
\hline Sig. (1-tailed) & $\begin{array}{l}\text { Total Score } \\
\text { Middle Term } \\
\text { points }\end{array}$ & .000 & .000 & .000 & .000 \\
\hline \multirow[t]{2}{*}{$N$} & Total Score & 130 & 130 & 111 & 111 \\
\hline & $\begin{array}{l}\text { Middle Term } \\
\text { points }\end{array}$ & 130 & 130 & 111 & 111 \\
\hline
\end{tabular}

As indicated by Pearson correlation outputs, there is a high positive correlation between middle term points and total score variables, $r=.846, n=130, p<.005$, where increases in middle term points were associated with increases in total score values.

Table 7: Bivariate regression outputs of the relationships between middle term points and total score variables

Model Summary_Experimental group

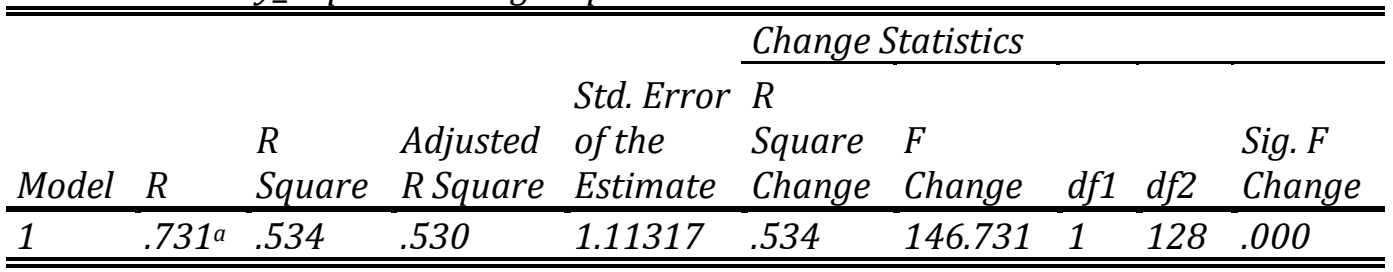

a. Predictors: (Constant), Middle Term points

Model Summary_ Control group

\begin{tabular}{|c|c|c|c|c|c|c|c|c|c|}
\hline \multirow[b]{2}{*}{ Model } & \multirow[b]{2}{*}{$R$} & \multirow[b]{2}{*}{$\begin{array}{l}R \\
\text { Square }\end{array}$} & \multirow[b]{2}{*}{$\begin{array}{l}\text { Adjusted } \\
R \text { Square }\end{array}$} & \multicolumn{5}{|c|}{ Change Statistics } & \multirow[b]{2}{*}{$\begin{array}{l}\text { Sig. F } \\
\text { Change }\end{array}$} \\
\hline & & & & $\begin{array}{l}\text { Std. Error } \\
\text { of the } \\
\text { Estimate }\end{array}$ & $\begin{array}{l}R \\
\text { Square } \\
\text { Change }\end{array}$ & $\begin{array}{l}F \\
\text { Change }\end{array}$ & $d f 1$ & $d f 2$ & \\
\hline 1 & $.846^{a}$ & .716 & .714 & 1.30420 & .716 & 275.242 & 1 & 109 & .000 \\
\hline
\end{tabular}

a. Predictors: (Constant), Middle Term points

As shown in Table 7, the total variance of total score levels explained by middle term points (the model) is $53.4 \%$ for the experimental group, and $71.6 \%$ for the control group, $\mathrm{F}(1,146.731 ; 1,275.242), \mathrm{p}<.005$, the other variance may be explained by other variables. This indicates that middle term points influence strongly the total score of students' academic performance.

Table 8: Beta standardized coefficients of the relationships between middle term points and total score variables

Coefficients ${ }^{a}$ Experimental group

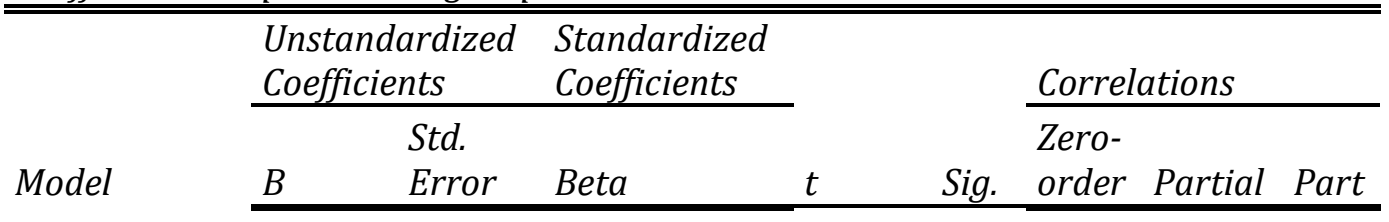




\begin{tabular}{|c|c|c|c|c|c|c|c|c|}
\hline 1 (Constant) & 2.903 & .314 & & 9.232 & .000 & & & \\
\hline $\begin{array}{l}\text { Middle } \\
\text { Term } \\
\text { points }\end{array}$ & 1.579 & .130 & .731 & 12.113 & .000 & .731 & .731 & .731 \\
\hline
\end{tabular}

a. Dependent Variable: Total Score

Coefficients ${ }_{-}$Control group

\begin{tabular}{|c|c|c|c|c|c|c|c|c|}
\hline \multirow[b]{2}{*}{ Model } & \multicolumn{2}{|c|}{$\begin{array}{l}\text { Unstandardized } \\
\text { Coefficients }\end{array}$} & $\begin{array}{l}\text { Standardized } \\
\text { Coefficients }\end{array}$ & \multirow[b]{2}{*}{$t$} & \multirow[b]{2}{*}{ Sig. } & \multicolumn{3}{|c|}{ Correlations } \\
\hline & $B$ & $\begin{array}{l}\text { Std. } \\
\text { Error }\end{array}$ & Beta & & & $\begin{array}{l}\text { Zero- } \\
\text { order }\end{array}$ & Partial & Part \\
\hline 1 (Constant) & 2.124 & .294 & & 7.234 & .000 & & & \\
\hline $\begin{array}{l}\text { Middle } \\
\text { term } \\
\text { points }\end{array}$ & 2.208 & .133 & .846 & 16.590 & .000 & .846 & .846 & .846 \\
\hline
\end{tabular}

a. Dependent Variable: Total Score

As shown in Table 8, the Beta Standardized coefficient (.731) for the experimental group, and (.846) for the control group of middle term points explains respectively $73.1 \%$ and $84.6 \%$ of the variance in the total score of their academic performance. The result was consistent with previously reported works (Guinocor, Almerino, Mamites, Lumayag, Villaganas, \& Capuyan, 2020; Rudd, \& Honkiss, 2020; Renes et al., 2020; Nadasen, \& List, 2016; Danilowicz-Gösele, Lerche, Meya, \& Schwager, 2017; Kleemola, \& Hyytinen, 2019; Drago, Rheinheimer, \& Detweiler, 2018; Balkis, \& Duru, 2017; Stone, Shaner, \& Fendrick, 2018; Carson, \& Reed, 2015; Iscan, \& Balyer, 2019), who argued that middle term points predict the total score of academic performance. In conclusion hypothesis \# 2: The variance in the total score is explained by middle term points in the context of face-to-face and online teaching, which is supported.

\section{Conclusions and Implications}

The purpose of the study is to investigate the differences between face-to-face and online teaching, as well as the effect of middle term points in total score in the context of face-to-face and online teaching. The prior assumption was that there are differences between face-to-face and online teaching and that middle term points impact the total score of students' academic performance. The study found that $17.7 \%$ of the experimental group and $13.5 \%$ of the control group achieved a low level of online teaching vs face to face teaching attendance; $37.7 \%$ of the experimental group and $44.1 \%$ of the control group achieved medium level, and $44.6 \%$ of the experimental group and $42.3 \%$ of the control group achieved a high level of online teaching vs face to face teaching attendance. It is found that $17.7 \%$ of online teaching group and $40.5 \%$ of face-to-face teaching group achieved a low level of middle term points; $35.4 \%$ of online teaching group and $16.2 \%$ of face-to-face achieved medium 
level, and $46.9 \%$ of online teaching group and $42.3 \%$ of face-to-face teaching group achieved a high level of middle term points. The results showed that $19.2 \%$ of online teaching group and $32.4 \%$ of face-to-face teaching group failed; $20.7 \%$ of online teaching group and $23.4 \%$ of face-to-face group achieved very low or low level; $50 \%$ of online teaching group and $9.9 \%$ of face-to-face group achieved lower or uppermedium level, and $17.2 \%$ of an online group and $34.2 \%$ of face-to-face group achieved a high or very high level.

It is revealed that for the experimental group of those having passed was equal to 105 , while the sample mean of those failing the course was 25; meanwhile, for the control group the sample mean of those having passed was equal to 75 , while the sample means of those failing the course was 36. The $t$ value obtained for the experimental group is equal to -13.056, on 128 degrees of freedom, and -10.476, on 109 degrees of freedom for the control group, with an associated $p$-value of 0.000 in two cases. The study shows, that there is a mean difference in the population or, equivalently, that the two-sample means were drawn from different populations. The study showed a high positive correlation between middle term points and total score variables, $\mathrm{r}=.846$ for the experimental group and $\mathrm{r}=.731$ for the control group, where increases in middle term points were associated with increases in total score values. The total variance of total score levels explained by middle term points (the model) is $53.4 \%$ for the experimental group, and $71.6 \%$ for the control group, the other variance may be explained by other variables. Beta Standardized coefficient of middle term points explains $84.6 \%$ of the variance in the total score of their academic performance for the experimental group and $73.1 \%$ for the control group. This indicates that middle term points influence strongly the total score of students' academic performance. The future researchers may investigate the impact of other variables on students' academic performance. The results of this study also have important implications for practice. The important interventions should be designed to support students because it is confirmed by this study that middle term points impact the total score of students' academic performance. Overall, the findings of this study enhanced theoretical and practical understanding as middle term points are an important variable that impacts academic performance.

\section{References}

[1] Abdullah, N. A., \& Mirza, M. S. (2019). Predicting Academic Performance in Undergraduate Online Degree Programs from Previous Academic Achievement in Pakistan. Pakistan Journal of Distance \& Online Learning,5(2), pp. 209-222.

[2] Anderton, R. S. (2017). Identifying Factors That Contribute to Academic Success in First-Year Allied Health and Science Degrees at an Australian University. Australian Journal of Education, 61(2), pp. 184-199. 
[3] Arco-Tirado, J. L., Fernández-Martín, F. D., \& Hervás-Torres, M. (2020). Evidence-Based Peer-Tutoring Program to Improve Students' Performance at the University.

[4] Asian Journal of Education and Training, 6(3), pp. 461-467.

[5] Balkis, M., \& Duru, E. (2017). Gender Differences in the Relationship between Academic Procrastination, Satisfaction with Academic Life and Academic Performance. Electronic Journal of Research in Educational Psychology, 15(1), pp. 105-125.

[6] Bayrakdaroglu, Y., Hekim, H. (2020). Examination of Pre-Service Teachers' Stress Levels towards Academic Expectations and Goal Commitment in Terms of Various Variables.

[7] Butler, J. (2020). Learning to Lead: A Discussion of Development Programs for Academic Leadership Capability in Australian Universities. Journal of Higher Education Policy and Management, 42(4), pp. 424-437.

[8] Carson, R. D., \& Reed, P. A. (2015). Pre-College Career Guidance on Student Persistence and Performance at a Small Private University. Career and Technical Education Research, 40(2), pp. 99-112.

[9] Cheung, A. (2021). Language Teaching during a Pandemic: A Case Study of Zoom Use by a Secondary ESL Teacher in Hong Kong. RELC Journal. https://doi.org/10.1177/0033688220981784.

[10] Conceição, S. C. O. (2006). Faculty Lived Experiences in the Online Environment. Adult Education Quarterly, 57(1), pp. 26-45. https://doi.org/10.1177/1059601106292247.

[11] Craft, J. A. (2019). Academic Performance of Low-SES Students at an Australian University Satellite Campus. Studies in Higher Education, 44(8), pp. 1372-1385.

[12] Danilowicz-Gösele, K., Lerche, K., Meya, J., \& Schwager, R. (2017). Determinants of Students' Success at University. Education Economics, 25(5), pp. 513-532.

[13] Dhawan, S. (2020). Online Learning: A Panacea in the Time of COVID-19 Crisis. Journal of Educational Technology Systems, 49(1), pp. 5-22. https://doi.org/10.1177/0047239520934018.

[14] Drago, A., Rheinheimer, D. C., \& Detweiler, T. N. (2018). Effects of Locus of Control, Academic Self-Efficacy, and Tutoring on Academic Performance. Journal of College Student Retention: Research, Theory \& Practice, 19(4), pp. 433-451.

[15] Elder, A. C. (2021). Holistic Factors Related to Student Persistence at a Large, Public University. Journal of Further and Higher Education, 45(1), pp. 65-78.

[16] Ferrão, M., \& Almeida, L. (2019). Differential Effect of University Entrance Score on First-Year Students' Academic Performance in Portugal. Assessment \& Evaluation in Higher Education, 44(4), pp. 610-622.

[17] Guinocor, M., Almerino, P., Mamites, I., Lumayag, C., Villaganas, M. A., \& Capuyan, M. (2020). Mathematics Performance of Students in a Philippine 
State University. International Electronic Journal of Mathematics Education, 15(3).

[18] Heble, A. (2007). Teaching Literature Online to Arab Students: Using technology to overcome cultural restrictions. Arts and Humanities in Higher Education, 6(2), pp. 219-226.

[19] Iscan, B., \& Balyer, A. (2019). Foundation University Students' Consumer Orientation and Learner Identity Levels and Their Correlations with Academic Performance. Eurasian Journal of Educational Research, 84, pp. 7192.

[20] Kite, J., Schlub, T. E., Zhang, Y., \& Choi, S. (2020). Exploring lecturer and student perceptions and use of a learning management system in a postgraduate public health environment. E-Learning and Digital Media, 17(3), pp. 183-198. https://doi.org/10.1177/2042753020909217.

[21] Kleemola, K., \& Hyytinen, H. (2019). Exploring the Relationship between Law Students' Prior Performance and Academic Achievement at University. Education Sciences, 9.

[22] Kohnke, L., \& Moorhouse, B. M. (2020). Facilitating Synchronous Online Language Learning through Zoom. RELC Journal. https://doi.org/10.1177/0033688220937235.

[23] Lessard, L. M., \& Juvonen, J. (2019). Cross-Class Friendship and Academic Achievement in Middle School. Developmental Psychology, 55(8), Pp. 16661679.

[24] Martínez, I. M., Youssef-Morgan, C. M., Chambel, M. J., \& Marques-Pinto, A. (2019). Antecedents of Academic Performance of University Students: Academic Engagement and Psychological Capital Resources. Educational Psychology, 39(8), pp. 1047-1067

[25] Meijer, E., Cleiren, M. P. H. D., Dusseldorp, E., Buurman, V. J. C., Hogervorst, R. M., \& Heiser, W. J. (2019). Cross-Validated Prediction of Academic Performance of First-Year University Students: Identifying Risk Factors in a Nonselective Environment. Educational Measurement: Issues and Practice, 38(1), pp. 36-47.

[26] Moorhouse, B. L., Li, Y., \& Walsh, S. (2021). E-Classroom Interactional Competencies: Mediating and Assisting Language Learning During Synchronous Online Lessons. RELC Journal. https://doi.org/10.1177/0033688220985274.

[27] Nadasen, D., List, A. (2016). Using Community College Prior Academic Performance to Predict Re-Enrollment at a Four-Year Online University. Online Learning, 20(2), pp. 120-133.

[28] Pakistan Journal of Distance and Online Learning, 5(2), pp. 209-222.

[29] Pokhrel, S., \& Chhetri, R. (2021). A Literature Review on Impact of COVID-19 Pandemic on Teaching and Learning. Higher Education for the Future, 8(1), pp. 133-141. https://doi.org/10.1177/2347631120983481. 
[30] Renes, E., Prieto, B., López, M., Fresno, J. M., González-Raurich, M., Tornadijo, M. E., Prieto, M., \& Álvarez-Ordóñez, A. (2020). Identification of Study Habits and Skills Associated with the Academic Performance of Bachelor's Degree Food Science and Technology Students at the University of León (Spain). Journal of Food Science Education, 19(4), pp. 250-262.

[31] Rudd, M., Honkiss, L. (2020). Analyzing the Correlation between English Proficiency and Academic Performance among Thai University Students. Athens Journal of Education, 7(1), pp. 123-137.

[32] Scales, P. C., Van Boekel, M., Pekel, K., Syvertsen, A. K., \& Roehlkepartain, E. C. (2020). Effects of Developmental Relationships with Teachers on MiddleSchool Students' Motivation and Performance. Psychology in the Schools, 57(4), pp. 646-677.

[33] Senior, R. (2010). Connectivity: A Framework for Understanding Effective Language Teaching in Face-to-face and Online Learning Communities. RELC Journal, 41(2), pp. 137-147. https://doi.org/10.1177/0033688210375775.

[34] Smith, M. O., Giugliano, A., \& DeOrio, A. (2018). Long Term Effects of Pair Programming. IEEE Transactions on Education, 61(3), pp. 187-194.

[35] Stone, K. L., Shaner, S. E., \& Fendrick, C. M. (2018). Improving the Success of First Term General Chemistry Students at a Liberal Arts Institution. Education Sciences, 8.

[36] Wang, C. H., \& Lin, H. C. K. (2017). Constructing an Affective Tutoring System for Designing Course Learning and Evaluation. Journal of Educational Computing Research, 55(8), pp. 1111-1128. https://doi.org/10.1177/0735633117699955.

[37] Wanzer, D., Postlewaite, E., \& Zargarpour, N. (2019). Relationships among Noncognitive Factors and Academic Performance: Testing the University of Chicago Consortium on School Research Model. AERA Open, 5(4).

[38] Zhao, Y., Tang, Y., Liu, F., Peng, Z., Kong, J., Huang, J., \& Tong, Z. (2021). Research and practice of online emergency teaching based on electronic information technology under the influence of COVID-19, The International Journal of Electrical Engineering \& Education. https://doi.org/10.1177/0020720920985048. 